\title{
First tentative signs of therapeutic promise
}

Washington

THE US Public Health Service last week announced that azidothymidine, or AZT, is the first therapeutic agent to show promise in treating victims of AIDS (acquired immune deficiency syndrome). Phase II clinical trials have shown such encouraging results that the health service has modified the studies in mid-stream to enable the placebo control group to be offered the drug. Burroughs Wellcome, manufacturer of AZT, said it would make the drug available to "a certain narrow category of patients with AIDS", but no more than 6,000 individuals may fit the criteria. And hobbled by a world-wide shortage of thymidine, an essential ingredient of the drug, the company may be hard pressed to keep its pledge.

All those concerned are eager to point out that there is no evidence, as yet, that the drug is a cure for the disease. What the trials have shown so far is merely that it prolongs the lives of an important subgroup of those infected.

Data released by Burroughs Wellcome and the health service last Friday reveal that, in tests involving 282 patients, AIDS victims receiving AZT had "a significantly lower mortality rate than those receiving placebo". During the course of the sixmonth study, 16 deaths occurred in the placebo group and only one in the group receiving AZT, whose members also showed a lower incidence of lymphomas, Kaposi's sarcoma and opportunistic infection. They gained weight and showed some improvement of immune function. The Data Safety Monitoring Board last week decided that it would be unethical to continue to withhold the drug from the placebo group.

The government and corporate teams involved in AZT testing also agreed to extend investigational new drug treatment to all individuals belonging to the trial subgroup deriving the greatest benefit from the use of the drug during the clinical trials. This group consists of AIDS victims who have contracted Pneumocycstis carinii, which accounts for about 60 per cent of the 11,000 living AIDS patients in the United States, according to Anthony Fauci, director of the National Institute of Allergy and Infectious Diseases. People would be given the drug only on the recommendation of a licensed physician.

AZT acts by competitive inhibition of reverse transcriptase, the enzyme that converts the RNA of retroviruses such as that responsible for AIDS into DNA which, incorporated in the genome of the infected cell, will ensure the replication of the virus. As a nucleoside analogue, AZT gets incorporated in the DNA strand where its unruly structure halts transcription and hence virus replication. There is evidence that AZT can prevent further deterioration of the immune system, and even allow some regeneration, according to Samuel Broder, deputy clinical director at the National Cancer Institute.

But, if AZT interferes with the replication of retroviral genomes, why does it not also interfere with the polymerase enzymes essential to normal cell function? Broder said polymerases are much less sensitive to the drug, and that this scenario might explain the bone marrow suppression observed in some patients taking AZT. Indeed, anaemia and low neutrophil and granulocyte counts are the most important side effects of AZT.

Because the phase II trials spanned only six months, little is yet known about the long-term effects such as toxicity, tolerance and sustained response. Nor is it clear that AIDS patients outside the group selected for the trials will reap the same benefits from the drug.

Even if further studies show that AZT is no more promising than in the first round of clinical trials, there may not be enough of it to go around. Thymidine, the primary raw material used in AZT synthesis, is usually extracted from herring sperm and is becoming more and more difficult to get, according to Burroughs Wellcome's head of research, David Barry. AZT synthesis tales 26 steps, several months and "many millions of dollars" to complete, Barry says. The company seems confident that it can meet the demand for treatments over the next few months, but it may be scrambling when the Food and Drug Administration approves AZT for more general release. Yet Broder thinks approval may come as early as December.

In the light of this potential shortage, many AIDS researchers are stressing the need to continue with tests on other drugs. They fear that reports of AZT's success are bound to make research initiatives more difficult.

In Britain, Burroughs Wellcome's parent Wellcome Research Foundation expects permission to begin controlled clinical studies next month, yet the company's supply of AZT in Britain is "tiny", according to David Langford, Wellcome's head of clinical immunology. Langford says the unexpected efficacy of AZT has "truncated" attempts to develop more efficient syntheses.
Arms control \section{Stockholm talks succeed at last}

THE agreement reached in Stockholm at the week-end is without precedent among arms control agreements, both in its provisions requiring advance notification of conventional troop movements and the detailed provisions for on-site inspection, demands for which may be made by any of the 35 signatories of the treaty. The agreement covers land forces only, but the territory between the Urals and the Atlantic.

The negotiations, which lasted close on three years, are an offshoot of the Helsinki accords of 1978, involving all European states (except Albania), the Soviet Union and the United States. The Helsinki documents required that the member states should explore technical schemes for building confidence and security in Europe. Progress at Stockholm, much of which has been squeezed into the past few months, seems to have been spurred by next month's deadline, when an account of the talks has to be given to a Conference on Security and Cooperation in Europe meeting in Vienna.

The chief provisions of the agreement are that all signatories should notify all others of military movements involving more than 13,00 people (or of 3,000 parachutists or troops landing from amphibious craft). If the numbers of people involved exceed 17,000 , observers from all other member states will be invited to attend to satisfy themselves that what is afoot cannot be counted threatening.

These numbers are approximately equal to but somewhat larger than the numerical strength of an army division, and have been the chief bone of contention at Stockholm in the past six months. Western powers had been seeking a number so small, perhaps as low as 8,000 , that single Soviet divisions would be caught. But the numbers are much smaller than originally offered by the Soviet side.

All signatories of the treaty will be required to produce, on 15 November each year, an annual calendar of planned troop movements in the year ahead. Movements or concentrations of 40,000 troops will have to be notified at least a year in advance, while movements of more than 70,000 troops will have to be announced in the calendar two years in advance.

Apart from the obligation to invite observers to exercises involving more than 17,000 land troops, the treaty will also give member states the right to demand inspections of suspicious events (but no member will be required to host more than three inspections a year). These provisions importantly treat all members of the Warsaw Pact and the North Atlantic Treaty Organization on an equal footing. 